Tropical Journal of Pharmaceutical Research January 2018; 17 (1): 53-63

ISSN: $1596-5996$ (print); 1596-9827 (electronic)

(c) Pharmacotherapy Group, Faculty of Pharmacy, University of Benin, Benin City, 300001 Nigeria.

Available online at http://www.tjpr.org

Original Research Article

http://dx.doi.org/10.4314/tjpr.v17i1.9

\title{
Novel hydroquinone derivatives alleviate algesia, inflammation and pyrexia in the absence of gastric ulcerogenicity
}

\author{
Khwaja Fawad', Nazar UI Islam², Fazal Subhan ${ }^{1 *}$, Muhammad Shahid ${ }^{1,2}$, \\ Gowhar Ali ${ }^{1}$, Faiz-Ur Rahman ${ }^{3}$, Wajahat Mahmood ${ }^{4}$, Nisar Ahmad ${ }^{1}$ \\ ${ }^{1}$ Department of Pharmacy, University of Peshawar, Peshawar 25120, ${ }^{2}$ Department of Pharmacy, Sarhad University of Science \\ and Information Technology, Peshawar 25000, Khyber Pakhtunkhwa, Pakistan, ${ }^{3}$ Department of Chemistry, Fudan University, \\ 220 Handan Road, Shanghai 200433, China, ${ }^{4}$ Department of Pharmacy, COMSATS Institute of Information Technology, \\ Abbottabad, Pakistan
}

*For correspondence: Email: fazal_subhan@upesh.edu.pk; Tel: +9291216750

\begin{abstract}
Purpose: To synthesize and characterize novel hydroquinone compounds that exhibit an aspirin-like pharmacological profile devoid of ulcerogenic side effects.

Methods: Two novel hydroquinone derivatives, viz, 2,5-bis(piperidinomethyl)hydroquinone and 2,5bis(pyrrolidinomethyl)hydroquinone, were synthesized by refluxing hydroquinone, paraformaldehyde and secondary amines (piperidine or pyrrolidine) in ethanol. The structures were authenticated by infrared (IR) spectroscopy, elemental analysis, mass spectrometry (MS) and $1 \mathrm{H}$ and $13 \mathrm{C}$ nuclear magnetic resonance (NMR) spectroscopic techniques. The synthesized derivatives were evaluated for antinociceptive, anti-inflammatory and antipyretic activities along with gastric-ulcerogenicity using wellknown testing paradigms. Aspirin served as reference standard.

Results: The newly synthesized hydroquinone derivatives, significantly attenuated tonic visceral chemically-induced nociception at $10 \mathrm{mg} / \mathrm{kg}(p<0.01, p<0.001), 20$ and $40 \mathrm{mg} / \mathrm{kg}(p<0.001)$, inhibited the temporal-inflammatory reaction at $50 \mathrm{mg} / \mathrm{kg}(2-5 \mathrm{~h}, p<0.05, p<0.001), 100$ and 150 $\mathrm{mg} / \mathrm{kg}(1-5 h, p<0.05, p<0.01, p<0.001)$ in addition to alleviating the febrile-response at test doses during $0.5 h(p<0.05, p<0.01, p<0.001), 1$ and $1.5 h(p<0.001)$ of the study period. The synthesized compounds exhibited improved gastric tolerability profile since they were devoid of aspirin-associated biochemical and ulcerative changes. The in silico studies predicted high binding affinity of the hydroquinone derivatives to the active site of the cyclooxygenase 2 (COX-2) enzyme.

Conclusion: The synthesized hydroquinone compounds possess analgesic, antipyretic and antiinflammatory properties with low gastric-ulcerogenic potential. This may be credited to preferential inhibition of the COX-2 enzyme and the beneficial basic rather than acidic chemical nature of the compounds. However, further molecular studies are required to substantiate these findings.
\end{abstract}

Keywords: 2,5-Bis(piperidinomethyl)hydroquinone], 2,5-Bis(pyrrolidinomethyl)hydroquinone, Antiinflammatory, Antinociceptive, Antipyretic, Gastric-ulcerogenicity, Algesia

\begin{abstract}
This is an Open Access article that uses a funding model which does not charge readers or their institutions for access and distributed under the terms of the Creative Commons Attribution License (http://creativecommons.org/licenses/by/4.0) and the Budapest Open Access Initiative (http://www.budapestopenaccessinitiative.org/read), which permit unrestricted use, distribution, and reproduction in any medium, provided the original work is properly credited.

Tropical Journal of Pharmaceutical Research is indexed by Science Citation Index (SciSearch), Scopus, International Pharmaceutical Abstract, Chemical Abstracts, Embase, Index Copernicus, EBSCO, African Index Medicus, JournalSeek, Journal Citation Reports/Science Edition, Directory of Open Access Journals (DOAJ), African Journal Online, Bioline International, Open-J-Gate and Pharmacy Abstracts
\end{abstract}




\section{INTRODUCTION}

Non-steroidal anti-inflammatory drugs (NSAIDs) are classic therapeutic agents used predominantly for inflammation, pyrexia and mild to moderate pain [1]. However, their clinical usefulness is limited by accompanying side effects, which include gastric ulceration, bleeding from the gastrointestinal tract, cardiovascular problems and renal complications [2,3]. This is a major restraint on the remedial application of NSAIDs. Therefore, there is a need for therapeutic compounds that are efficacious in alleviating inflammation, pain and pyrexia, while exhibiting fewer gastrointestinal side effects.

Hydroquinone or benzene-1,4-diol may be obtained by hydrolysis of arbutin (Figure 1A) using the enzyme, $\beta$-glucosidase [4]. Arbutin is a glycoside of hydroquinone which may be extracted from the leaves of bearberry, Arctostaphylos uvaursi [5]. It has antiinflammatory and anti-tyrosinase activities, and is devoid of any gastric toxicity $[6,7]$. In this respect, hydroquinone has anti-inflammatory properties which are mediated through inhibition of proinflammatory cytokines (TNF- $\alpha$, IL-1 $\beta$, IL-6) or via release of toxic substances like nitric oxide (NO) [8]. The hydroquinone ring structure is very interesting because it lends itself to many pharmacologically active moieties. For example, acetaminophen, a well-known analgesic, has been synthesized by substitution in the hydroquinone structure [9].

The compounds reported in our study, viz, 2,5bis(piperidinomethyl)hydroquinone (compound (1)) and 2,5-bis(pyrrolidinomethyl)hydroquinone (compound (2)) are derived from hydroquinone ring substitution, via integration of pharmacologically important piperidine and pyrrolidine heterocyclic moieties. It has been reported that chemical compounds containing these moieties possess diverse pharmacological properties including antinociceptive, antiinflammatory and antipyretic activities $[10,11]$. Similarly, pyrrolidine ring-containing compounds have been shown to be effective against various disease conditions such as migraine, bipolar disorders, tuberculosis and cancer [12,13]. In this connection, piperidine and pyrrolidine heterocycles are considered as critical nuclei for novel drug design. These moieties associated with diverse pharmacological activities encouraged us to incorporate them into the basic hydroquinone structure. Therefore, hydroquinone derivatives were synthesized and their structures were confirmed by different spectroscopic methods (IR, ${ }^{1} \mathrm{H}-\mathrm{NMR},{ }^{13} \mathrm{C}-\mathrm{NMR}$, mass spectrometry and elemental analysis) and were then evaluated for antinociceptive, antipyretic and anti-inflammatory activities as well as any gastro-ulcerogenic proclivity, using in vivo testing paradigms. Additionally, the binding affinity of these compounds with cyclooxygenase (COX) enzymes (COX-1 and COX-2) was studied using a molecular docking simulation approach.

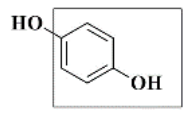

A

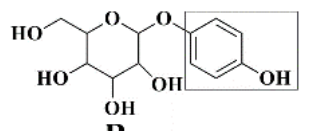

B

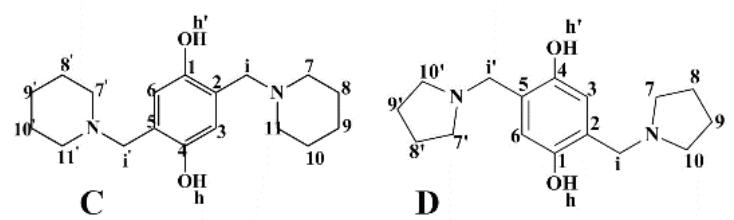

Figure 1: Chemical structures of hydroquinone $(A)$, arbutin (B), compound $\mathbf{1}(\mathrm{C})$ and compound 2 (D)

\section{EXPERIMENTAL}

\section{Instruments and apparatus}

A Nicolet 380 thermoscientific FTIR (USA) instrument was used for recording Infrared (IR) spectra. ${ }^{1} \mathrm{H}$ and ${ }^{13} \mathrm{C}$-NMR analyses (Bruker AVANCE $400 \mathrm{MHz}$, Germany) were conducted using DMSO- $\mathrm{d}_{6}$ or $\mathrm{D}_{2} \mathrm{O}$ as solvents. Mass spectra (ESI-MS) were obtained on a Bruker micrOTOF II (USA) mass spectrometer. Elemental analyses were performed on an Elementar Analysensysteme $(\mathrm{GmbH}$ VarioEL V4.01 20.Aug. 2002 (Germany) instrument operated in $\mathrm{CHN}$ mode. Histological slides were prepared with the help of a microtome (SLEE MAINZ, Germany).

\section{Synthesis of hydroquinone derivatives}

Hydroquinone derivatives were prepared by a simple reaction between secondary amine, paraformaldehyde and hydroquinone. While synthesizing these derivatives, quinone was amino methylated according to a known method [14] as given in Scheme 1. The synthesized compounds were obtained in a good yield.

\section{Compound 1 (2,5-bis(piperidinomethyl) hydroquinone)}

Piperidine $(20 \mathrm{mmol}, 1.96 \mathrm{~mL})$ and paraformaldehyde $(33.3 \mathrm{mmol}, 1 \mathrm{~g})$ were slowly mixed and then refluxed for $1 \mathrm{~h}$ to obtain a clear solution. The resulting solution was cooled to room temperature $\left(25{ }^{\circ} \mathrm{C}\right)$ and a solution of hydroquinone $(10 \mathrm{mmol}, 1.1 \mathrm{~g})$ in ethanol (100 $\mathrm{mL}$ ) was added to the above mixture. The mixture was stirred using a magnetic stirrer and 


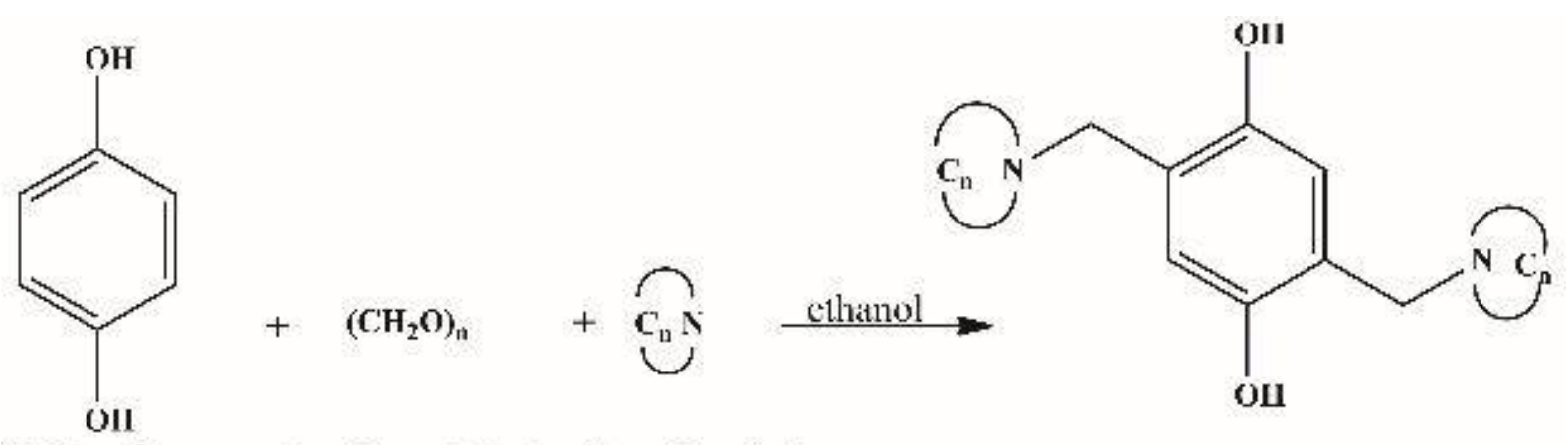

Ḩ̧droquinone 2,5-bis(aminomethyl)hydroquinone

$$
1,2
$$

Where; 1) $\mathrm{n}=4$, Compound 1

2) $\mathrm{n}=5$, Compound 2

Scheme 1: Synthetic route for compounds 1 and 2

was monitored by taking samples for TLC at $1 \mathrm{~h}$ interval. The reaction was completed after 8 hours. After removal of solvent at ambient temperature, a brownish solid was obtained which was recrystallized three times with ethanol to obtain pure white crystals (Figure 1C).

\section{Compound 2 (2,5-bis(pyrrolidinomethyl) hydroquinone)}

A mixture of hydroquinone $(10 \mathrm{mmol}, 1.1 \mathrm{~g})$, pyrrolidine $(20 \mathrm{mmol}, 1.64 \mathrm{~mL})$ and paraformaldehyde $(33.3 \mathrm{mmol}, 1 \mathrm{~g})$ was refluxed in ethanol $(100 \mathrm{~mL})$ for $20 \mathrm{~h}$. The resulting solution was cooled to room temperature $\left(25^{\circ} \mathrm{C}\right)$ and filtered to obtain a brownish solid. The solid was recrystallized three times with ethanol in order to remove any entrapped impurity and to yield pure white crystals of compound (2) (Figure 1D).

\section{Animals}

BALB/c mice and Sprague-Dawley rats of either sex were used and housed separately as 6 animals per cage, under laboratory conditions of $22 \pm 2{ }^{\circ} \mathrm{C}, 40-60 \%$ relative humidity $(\mathrm{RH})$ and $12 \mathrm{~h}$ light/12 $\mathrm{h}$ dark cycle. The experimental animals were provided free access to food and water and were kept under the standard laboratory conditions in the animal housing facility established at Department of Pharmacy, University of Peshawar, Pakistan. Prior to commencement of the experiments, animals were allowed to habituate for $2 \mathrm{~h}$ to the laboratory conditions. The experimental procedures reported below were approved by the Institutional Animals Ethics Committee with registration no. 11/ EC-15/Pharm and performed in compliance with the UK approved guidelines for laboratory animals [15].

\section{Acute toxicity test}

Mice (25-30 g, $n=6$ ) were administered with test compounds intraperitoneally (i.p.) at 50, 100, 250 and $500 \mathrm{mg} / \mathrm{kg}$. Morbidity was observed continuously for the first $2 \mathrm{~h}$, while mortality up to $24 \mathrm{~h}$ after dose administration. The animals were observed for impulsive activity, cyanosis, convulsions, catalepsy, contortions, tail pinch response, and abnormal behavior [16].

\section{Determination of antinociceptive activity}

\section{Acetic acid-induced abdominal constriction assay}

BALB/c mice (18-22 g, $n=6$ ) were randomly divided into ten groups. Group I was administered normal saline (i.p.). Group II-IV received standard aspirin at 10,20 and $40 \mathrm{mg} / \mathrm{kg}$ (i.p.), respectively. Similarly, groups V-VII received compound (1) and groups VIII-X received compound (2) at 10,20 and $40 \mathrm{mg} / \mathrm{kg}$ (i.p.), respectively. Thirty min after treatment, $1 \%$ acetic acid (i.p.) was injected and after a further 5 min, abdominal constrictions (writhes) for each group were determined and the behavior was observed for 20 min [17]. Percentage protection (PP) was calculated as in Eq 1.

$\mathrm{PP}=\{(1-\mathrm{Mt} / \mathrm{Mc})\} 100$

where $M t$ and $M c$ represented mean number of abdominal constrictions of the treated drug and the control group, respectively.

\section{Hot plate assay}

BALB/c mice (18-22 g, $n=6$ ) exhibiting a latency $<15 \mathrm{~s}$ signified by a hind limb flick, licking or jumping, when placed on the hot plate $(54.0 \pm$ 
$0.10^{\circ} \mathrm{C}$, Harvard apparatus, USA) were included in the study. Animals were administered compounds (1) or (2) (10, 20 and $40 \mathrm{mg} / \mathrm{kg}$, i.p.) or morphine (5 mg/kg, i.p.) and $30 \mathrm{~min}$ after each treatment, response latencies were noted at 30 , 60 and $90 \mathrm{~min}$. To avoid tissue injury, a $30 \mathrm{~s}$ cutoff time was imposed [18]. The percent antinociception (PA) was calculated as in Eq 2.

$\mathrm{PA}=\{(\mathrm{TI}-\mathrm{Cl} / \mathrm{Ct}-\mathrm{Cl})\} 100$

where $\mathrm{Tl}, \mathrm{Cl}$ and $\mathrm{Ct}$ represented test latency, control latency and cut-off time, respectively.

\section{Carrageenan induced inflammatory assay}

BALB/c mice (25 - $30 \mathrm{~g}, n=6$ ) were divided into ten groups in carrageenan-induced inflammatory assay. Group I received normal saline (i.p.). Groups II - IV received standard aspirin at 50, 100 and $150 \mathrm{mg} / \mathrm{kg}$ (i.p.), respectively. Similarly, groups V - VII received compound (1) and groups VIII-X received compound (2) at 50, 100 and $150 \mathrm{mg} / \mathrm{kg}$ (i.p.), respectively. One hour after treatment, each group received $1 \%$ carrageenan suspension, injected subcutaneously (s.c) into the planter region of the rear paw. Mean paw swelling was measured using a digital plethysmometer (Model LE 7500 Plan lab S.L, Italy) before carrageenan administration and thereafter at $1 \mathrm{~h}$ intervals for $5 \mathrm{~h}$ [19]. Inhibition of edema $(\mathrm{H})$ was calculated as in Eq 3.

$H(\%)=\{(A-B) / A\} 100$

where $A$ is the mean paw volume of control and $B$ represented the mean paw edema volume of the test group.

\section{Brewer's yeast induced pyrexia assay}

BALB/c mice $(25-30 \mathrm{~g})$ were divided into ten different groups of six animals per group. All animals were deprived of food with free access to water. The baseline rectal temperature of all mice was noted by inserting a lubricated digital thermometer probe (model CA92121, ACON Laboratories, USA) into the rectum (to a depth of $2 \mathrm{~cm}$ ) of each animal and then pyrexia was induced using a suspension of $20 \%$ Brewer's yeast (Merck, Germany, $10 \mathrm{~mL} / \mathrm{kg}$ ) by the subcutaneous route.

Any change in the rectal temperature of each animal was measured $24 \mathrm{~h}$ after Brewer's yeast administration and those animals which expressed a rise of 0.3 to $0.5{ }^{\circ} \mathrm{C}$ were selected for the study [20]. Group I was treated with normal saline (i.p.). Groups II - IV received aspirin (50, 100 and $150 \mathrm{mg} / \mathrm{kg}$, i.p, respectively), groups V-VII received compound (1) while the remaining groups (VIII - X) received compound (2) at doses of 50,100 and $150 \mathrm{mg} / \mathrm{kg}$, i.p., respectively. Following drug administration, the rectal temperature of each mouse was measured at $0.5,1$ and $1.5 \mathrm{~h}$. The mean decrease in rectal temperature across treated groups was compared relative to untreated controls.

\section{Assessment of gastric ulcerogenicity}

Sprague-Dawley rats (150 - $200 \mathrm{~g}, n=6$ ) were randomly divide to treatment groups and each animal was administered the following treatment once a day orally for 6 days as follows:

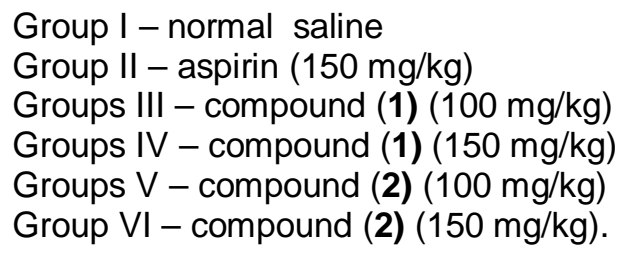

The last dose for each animal group was administered $1 \mathrm{~h}$ prior to pyloric ligation. At the end of the protocol, each rat was killed and the stomach mucosa was removed. The macroscopic injury was observed with 10x lens and ulcer severity was scored [21]. The gastric content was also collected and centrifuged for 10 min at $1,000 \mathrm{rpm}$ and the supernatant was taken apart. The volume $(\mathrm{ml}), \mathrm{pH}$, free acidity, total acidity and pepsin concentration of the gastric juice were determined using the procedures reported previously in our laboratory [22]. After centrifugation, the gastric juice volume was measured with a pipette and $\mathrm{pH}$ was determined with a digital $\mathrm{pH}$ meter. For determination of free acidity, $1 \mathrm{~mL}$ of supernatant was mixed with $2-3$ drops of Toper's reagent and was titrated against $0.01 \mathrm{~N} \mathrm{NaOH}$.

The changes in the color of solution from light red to canary yellow determined the free acidity. To this solution, two drops of phenolphthalein indicator were added and the titration process was continued until the appearance of permanent a pink color. The volume $(\mathrm{mL})$ of alkali utilized was noted and this represented the total acidity. For pepsin activity determination, the absorbance of protein was measured at 700 $\mathrm{nm}$ and the results were presented as micromoles of tyrosine liberated per $\mathrm{mL}$.

\section{Assessment of histopathological changes}

At the end of each experiment, the stomach specimens were fixed immediately in formalin (10 $\%$ neutrally buffered) for $48 \mathrm{~h}$, dehydrated in variant ethanol (50-100\%) solutions, cleared in 
$100 \%$ xylene and immersed in paraffin. Sections (5 $\mathrm{mm}$ thickness) were cleared, hydrated and then stained (hematoxylin and eosin) [23]. The prepared slides were evaluated for any histopathological changes.

\section{In silico studies}

The structures of cyclooxygenase-1 (COX-1) with bound Flurbiprofen (PDB ID 1CQE) and cyclooxygenase-2 (COX-2) enzyme with bound selective inhibitor (PDB ID 1CX2) were downloaded from the website (www.rcsb.org/pdb) of the Protein Data Bank (PDB) and the binding site residues of the receptors were identified. Bound ligands were then removed from the receptor binding site using discovery studio 4.0 (Dassault Systèmes BIOVIA, Discovery Studio Modeling Environment, Release 2017, San Diego: Dassault Systèmes, 2016).

The enzyme and ligand structures were then prepared for docking using Autodock Tools. The study ligands namely 2,5-bis(piperidinomethyl) hydroquinone (compound 1) and 2,5-bis (pyrrolidinomethyl)hydroquinone (compound 2) were then docked into the binding site of COX active sites using Autodock Vina [24]. Nine binding modes were proposed by the program and the binding mode with lowest binding energy and suitable interactions was selected and studied.

\section{Statistical analysis}

Statistical significance of pharmacological data was determined using one-way ANOVA followed by post hoc Dunnett's test. $P<0.05$ level was considered as significant. Data are expressed as mean $\pm \operatorname{SEM}(n=6)$.

\section{RESULTS}

\section{Spectral characteristics of synthesized molecules}

\section{Compound 1 (2,5-bis(piperidinomethyl) hydroquinone)}

White crystals; Yield: $56.0 \%$, m.p. $189.0{ }^{\circ} \mathrm{C}$. IR $(\mathrm{KBr}) v_{\max }$ : 3853, 2945, 1452, 1377, 1307, 1107, $988,879,787 \mathrm{~cm}^{-1}$. ${ }^{1} \mathrm{H}$ NMR $(400 \mathrm{MHz}$, DMSOd6) $\delta 2.39\left(\mathrm{t}, 8 \mathrm{H}, \mathrm{H}^{7}, 7^{\prime}, 11,1^{\prime}\right), 1.42-1.51(\mathrm{~m}, 12 \mathrm{H}$, $\left.\mathrm{H}^{8,} 8^{\prime}, 9,9^{\prime}, 10,10^{\prime}\right), 3.49$ (s, 4H, $\mathrm{H}^{\mathrm{i}, \mathrm{i}}$ ) $), 10.16$ (s, 2H, $\left.\mathrm{H}^{\mathrm{h}, \mathrm{h}}\right), 6.41\left(\mathrm{~s}, 2 \mathrm{H}, \mathrm{H}^{3,6}\right) .{ }^{13} \mathrm{C}$ NMR $\left(75 \mathrm{MHz}, \mathrm{D}_{2} \mathrm{O}\right)$ $\delta 24.08\left(2 \mathrm{C}, \mathrm{C}^{9,9}\right), 25.94\left(4 \mathrm{C}, \mathrm{C}^{8,8}, 10,10^{\prime}\right), 53.74$ $\left(4 \mathrm{C}, \mathrm{C}^{7}, 7^{\prime}, 11,11^{\prime}\right), 60.43\left(2 \mathrm{C}, \mathrm{C}^{\mathrm{i}, \mathrm{i}^{\prime}}\right), 115.92\left(2 \mathrm{C}, \mathrm{C}^{3}\right.$, 6), $121.82\left(2 \mathrm{C}, \mathrm{C}^{2,5}\right), 149.61\left(2 \mathrm{C}, \mathrm{C}^{1,4}\right)$. HRMS (ESI): calcd for $\mathrm{C}_{18} \mathrm{H}_{28} \mathrm{~N}_{2} \mathrm{O}_{2}$ 305.221: $[\mathrm{M}+\mathrm{H}]^{+}$, found: 305.224. Anal. Calcd. for $\mathrm{C}_{18} \mathrm{H}_{28} \mathrm{~N}_{2} \mathrm{O}_{2}$ : C, 71.02; H, 9.27; N, 9.20. Found: C, 70.90; H, 10.37; N, 9.38.

\section{Compound 2 (2,5-bis(pyrrolidinomethyl) hydroquinone)}

White crystals; Yield: $55.5 \%$ m.p. $153.8{ }^{\circ} \mathrm{C}$. IR $(\mathrm{KBr}) v_{\text {max }}: 3848,2801,1480,1389,1307,1198$, $888,833 \mathrm{~cm}^{-1}$. 'H NMR (400 MHz, DMSO-d6) $\delta$ 2.48-2.49 (t, 8H, $\left.\mathrm{H}^{7}, 7,10,10^{\prime}\right), 1.72-1.76(\mathrm{~m}, 8 \mathrm{H}$, $\left.\mathrm{H}^{8,8}, 9,9^{\prime}\right), 3.61\left(\mathrm{~s}, 4 \mathrm{H}, \mathrm{H}^{\mathrm{i}, \mathrm{i}^{\prime}}\right), 9.93\left(\mathrm{~s}, 2 \mathrm{H}, \mathrm{H}^{\mathrm{h}, \mathrm{h}^{\prime}}\right)$, $6.46\left(\mathrm{~s}, 2 \mathrm{H}, \mathrm{H}^{3},{ }^{6}\right) .{ }^{13} \mathrm{C}$ NMR $\left(75 \mathrm{MHz}, \mathrm{D}_{2} \mathrm{O}\right) \delta$ $23.60\left(4 \mathrm{C}, \mathrm{C}^{8,}, 8^{\prime}, 9^{\circ}, 9^{\prime}\right), 53.54\left(4 \mathrm{C}, \mathrm{C}^{7,7}, 10,0^{\prime}\right)$, $56.78\left(2 \mathrm{C}, \mathrm{C}^{\mathrm{i}, \mathrm{i}^{\prime}}\right), 115.47\left(2 \mathrm{C}, \mathrm{C}^{3,6}\right), 122.88(2 \mathrm{C}$, $\left.\mathrm{C}^{2,5}\right), 149.23\left(2 \mathrm{C}, \mathrm{C}^{1,4}\right)$. HRMS (ESI): calcd for $\mathrm{C}_{16} \mathrm{H}_{24} \mathrm{~N}_{2} \mathrm{O}_{2}$ 277.188: $[\mathrm{M}+\mathrm{H}]^{+}$, found: 277.191. Anal. Calcd. for $\mathrm{C}_{16} \mathrm{H}_{24} \mathrm{~N}_{2} \mathrm{O}_{2}: \mathrm{C}, 69.53 ; \mathrm{H}, 8.75$; N, 10.14. Found: C, 69.17; H, 9.16; N, 9.88.

\section{Acute toxicity}

Both compounds did not reveal any behavioral changes or mortality at doses up to $500 \mathrm{mg} / \mathrm{kg}$.

\section{Compounds (1) and (2) attenuated tonic visceral nociception}

As shown in Figure 2, a significant attenuation of tonic visceral nociception was produced by aspirin at doses of $10 \mathrm{mg} / \mathrm{kg}(p<0.01), 20$ and $40 \mathrm{mg} / \mathrm{kg}(p<0.001)$ and also the head to head doses of compound $(1)(p<0.001)$ in the acetic acid-induced abdominal constrictions assay. Likewise, compound (2) also afforded maximum protection against nociceptive behavior at the tested doses of $10 \mathrm{mg} / \mathrm{kg}(p<0.01), 20$ and 40 $\mathrm{mg} / \mathrm{kg}(p<0.001)$. In the hot plate test, both compounds (1) and (2) were inactive at all tested

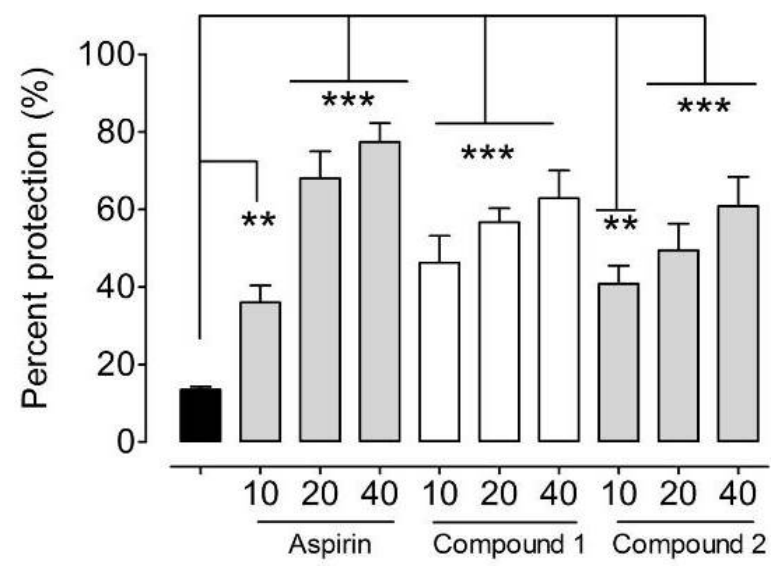

Figure 2: Antinociceptive effect of aspirin, compounds 1 and 2, at 10, 20 and $40 \mathrm{mg} / \mathrm{kg}$ (i.p.). Values are percent inhibition of abdominal constrictions \pm SEM ( $n$ $=6) ;{ }^{* *} p<0.01,{ }^{* * *} p<0.001$ as compared to saline treated control; $n=6$ 
doses against acute phasic nociception, however, in comparison morphine $(5 \mathrm{mg} / \mathrm{kg}$ ) provided significant protection against thermal hyperalgesia after $30,60 \mathrm{~min}(p<0.001)$ and 90 $\min (p<0.01)$ as shown in Figure 3.

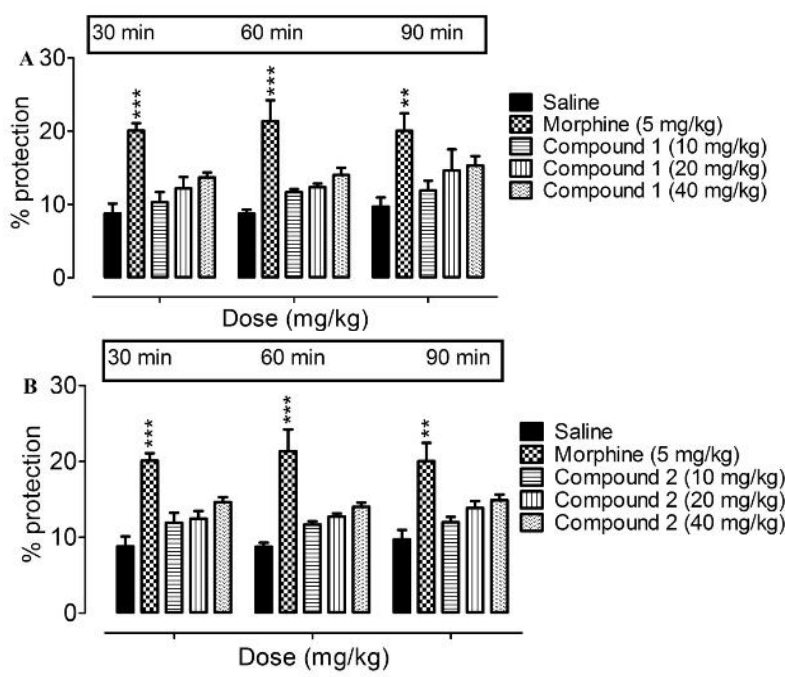

Figure 3: Antinociceptive effect of $(A)$ compound 1, and (B) compound 2, at 10, 20, $40 \mathrm{mg} / \mathrm{kg}$ (i.p.) in the hot plate assay. Values are percent response latencies \pm SEM of 6 mice per group; ${ }^{* *} p<0.01,{ }^{* * *} p<$ 0.001 as compared to saline treated control

\section{Compounds (1) and (2) alleviated temporal inflammatory response}

After $1 \mathrm{~h}$, a significant reduction in paw swelling was observed in response to doses of 100 and $150 \mathrm{mg} / \mathrm{kg}$ of aspirin $(p<0.05)$, compound (1) $(p<0.05)$ and compound $(2)(p<0.01, p<0.001)$. After $2 \mathrm{~h}$, all the test doses $(50 \mathrm{mg} / \mathrm{kg}, p<0.05$; 100 and $150 \mathrm{mg} / \mathrm{kg} ; p<0.01)$ of aspirin and compound (1) downgraded the inflammatory response. These doses of aspirin as well as compound (1) were more effective during the late phase of inflammation, where a significant diminution of the swelled paw was observed at 3 h $(p<0.05, p<0.01)$ and $4-5$ h $(p<0.001)$. Compound $(2)$ was more effective $(p<0.001)$ in decreasing the edema induced by the phlogistic agent and was able to counteract both early and late phases of inflammation (Figure 4).

\section{Compounds (1) and (2) suppressed yeast- induced pyrexia}

As shown in Figure 5 , after $0.5 \mathrm{~h}$, a significant decrease in the Brewer's yeast induced febrile response was observed in response to aspirin, compounds (1) and (2) at the tested doses of 50 $\mathrm{mg} / \mathrm{kg}(p<0.05, p<0.01), 100 \mathrm{mg} / \mathrm{kg}(p<0.01$, $p<0.001)$ and $150 \mathrm{mg} / \mathrm{kg}(p<0.001)$. As time progressed, the reduction in body temperature become even more highly significant and the antipyretic effect was even more marked after 1 and $1.5 \mathrm{~h}$ for aspirin, compounds (1) and (2), when evaluated at doses of $50,100 \mathrm{mg} / \mathrm{kg}(p<$ $0.01, p<0.001)$ and $150 \mathrm{mg} / \mathrm{kg}(p<0.001)$.

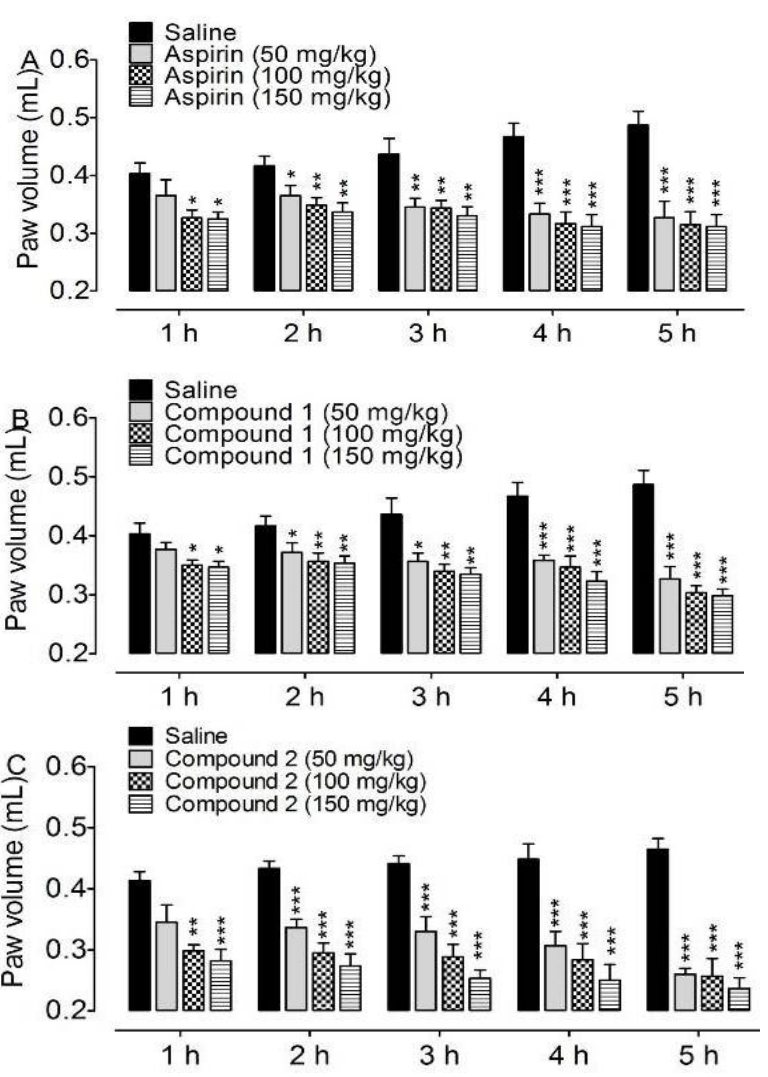

Figure 4: Anti-inflammatory effect of $(A)$ aspirin, $(B)$ compound 1 and $(C)$ compound 2, at 50, 100 and 150 $\mathrm{mg} / \mathrm{kg}$ (i.p.). Values are mean paw volume in $\mathrm{mL} \pm$ SEM $(\mathrm{n}=6) ;{ }^{\star} p<0.05,{ }^{* *} p<0.01,{ }^{* * *} p<0.001$ as compared to saline treated control

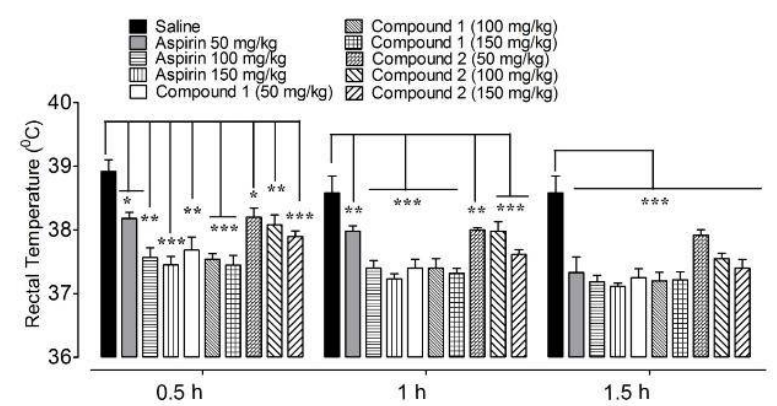

Figure 5: Antipyretic effect of aspirin, compounds 1 and 2, at 50, 100 and $150 \mathrm{mg} / \mathrm{kg}$ (i.p.). Values are mean rectal temperature in ${ }^{0} \mathrm{C}, \pm \operatorname{SEM}(\mathrm{n}=6) ;{ }^{*} p<$ $0.05,{ }^{* *} p<0.01,{ }^{* * *} p<0.001$ as compared to saline treated control

\section{Compounds (1) and (2) were devoid of gastric-ulcerogenicity}

Figure $6 \mathrm{~A}$ depicted the dose of $150 \mathrm{mg} / \mathrm{kg}$ of aspirin per day for a period of 6 consecutive days and it significantly increased the ulcer score $\left(F_{5,30}\right.$ $=7.79, p<0.001)$, the volume of gastric juice $\left(F_{5,30}=10.64, p<0.001\right.$, Figure $\left.6 \mathrm{~B}\right)$, gastric $\mathrm{pH}$ 
$\left(F_{5,30}=5.47, p<0.01\right.$, Figure $\left.6 \mathrm{C}\right)$, free acidity $\left(F_{5,30}=5.75, p<0.001\right.$, Figure $\left.6 D\right)$ and total acidity $\left(F_{5,30}=6.56, p<0.001\right.$, Figure $\left.6 \mathrm{E}\right)$, when compared to control. However, these parameters were unchanged with the tested compounds at 100 and $150 \mathrm{mg} / \mathrm{kg}$, and they were comparable to that of control animals. Moreover, the pepsin concentration was not affected in any of the treatment groups (Figure 6F).

Examination of gastric mucosa (photomicrographs) revealed an absence of morphological changes (hemorrhagic streaks or spot ulcers) in the stomach mucosa of animal groups treated with compounds (1) and (2) and saline. Nonetheless, visually noticeable changes were perceived in the mucosa of aspirin-treated group (Figure 7A - F).

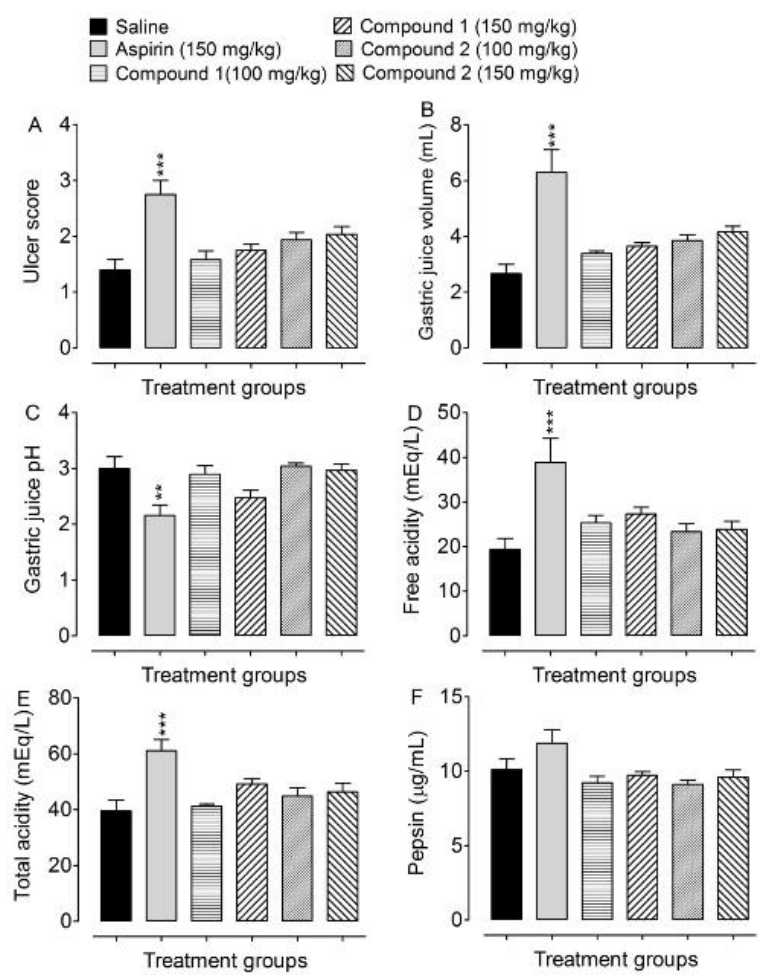

Figure 6: Ulcerogenicity of aspirin $(150 \mathrm{mg} / \mathrm{kg})$, compound 1 and compound $2(100,150 \mathrm{mg} / \mathrm{kg})$. Each bar represents (A) ulcer score, (B) gastric juice volume, (C) gastric $\mathrm{pH}$, (D) free acidity, (E) total acidity, and (F) pepsin concentration \pm SEM $(n=6)$; ${ }^{\star \star} p<0.01,{ }^{\star \star \star} p<0.001$, compared to saline control

Using light microscopy, the gastric mucosa of control rats revealed normal histo-architecture with undamaged structures and normal epithelial lining (Figure 7A1). The gastric mucosa of aspirin treated rats showed damaged mucosal epithelium, submucosal edema and inflammation at the ulcer site (Figure 7B1); whereas, rats administered compound 1 (100, $150 \mathrm{mg} / \mathrm{kg}$, Figure 7C1 and D1) and compound 2 (100, 150 $\mathrm{mg} / \mathrm{kg}$, Figure 7E1 and F1) exhibited no ulceration, and the histological appearance was similar to that of control animals.
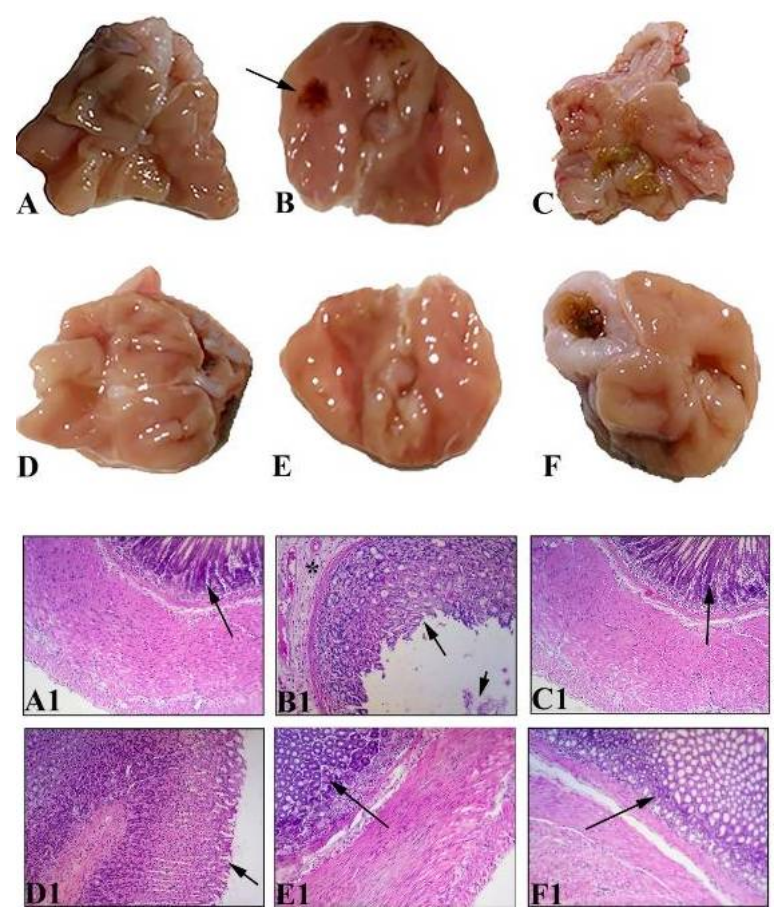

Figure 7: Gross appearance of stomach mucosa from groups of animals treated with $(A)$ saline control rats; (B) aspirin treated rats showing ulcer spots and bleeding; (C) compound 1 (100 mg/kg) treated rats; (D) compound $1(150 \mathrm{mg} / \mathrm{kg})$ treated rats; (E) compound 2 (100 mg/kg) treated rats, and (F) compound $2(150 \mathrm{mg} / \mathrm{kg})$ treated rat, which were essentially devoid of ulcers. Sections of gastric mucosa of control and experimental animals were stained by employing hematoxylin and eosin and were observed under light microscopy. (A1) The control group exhibited normal structure of the epithelial lining (arrowed). (B1) The aspirin (150 mg/kg) treated group displayed disruption and erosion of mucosa (large arrow), infiltration of red blood cells and lymphocytes in the submucosa (asterisk) along with necrotic debris visible in the lumen (small arrow) of the ulcer, while a normal gastric epithelial lining (arrows) was observed for (C1) compound 1 (100 mg/kg), (D1) compound 1 (150 mg/kg), (E1) compound 2 (100 mg/kg) and (F1) compound $2(150 \mathrm{mg} / \mathrm{kg})$ which are similar to that of control. Magnification: 10x

\section{Compounds (1) and (2) exhibited an antagonistic tendency against COX enzymes}

The active sites of both isoforms of COX were predominantly hydrophobic except for the Arg120 residue. The active site binding mechanism of NSAIDS to the COX isoforms involved extensive non-covalent pi-interactions, in addition to the charged interactions of the ionized carboxylic group of the NSAID with the protonated arginine side chain. 
The results of our docking study show that aspirin (2-Acetoxy Benzoic Acid) binds both of the cyclooxygenase isoforms. Aspirin was present near a Serine residue (SER 530) of the cyclooxygenase-2 enzyme, which is located outside the active site of the enzyme (Figure 8C). Aspirin is known to act through acetylation of this serine residue by the transfer of its own acetyl group. Our docking results predict binding of aspirin to SER 530 of both cyclooxygenase isoforms through the same mechanism. On other hand, compounds (1) and (2) showed higher affinity to the COX-2 isoform mainly due to $\mathrm{H}$ bonding with this enzyme. The most favourable binding modes of compounds (1) (Figure 8A) and compound (2) (Figure 8B) showed $\mathrm{H}$-bonding of the hydroxyl groups on the hydroquinone nucleus with the histidine residue (His 90 in compound 1) and tyrosine and arginine residues (Tyr 355 and ARG 120 in compound 2).

Compounds (1) and (2) were docked in the cavity of COX-1 enzyme. The binding to COX-1 is mainly of hydrophobic nature and binding energy to this enzyme is considerably higher as compared to the COX-2 isoform. Predictive insilico modelling divulged an absence of charged interactions between the molecules and the enzyme. However, an extensive hydrophobic interaction could be seen.

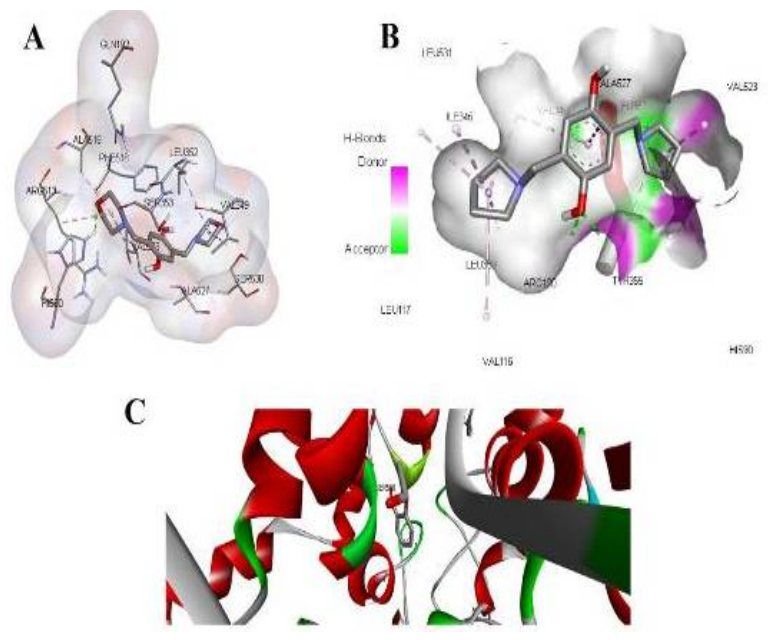

Figure 8: (A) Compound 1 in the cavity of COX-2. Hbond is represented by a green discontinuous line. $\mathrm{Pi}-$ alkyl and $\mathrm{Pi}-\mathrm{Pi}$ interactions are represented by grey discontinuous lines. (B) Compound 2 shows both $\mathrm{H}$ bonding and hydrophobic interactions with the active site of COX-2. Some of the surface is removed to show the binding mode of the compound clearly. $\mathrm{H}$ bond is represented by green discontinuous line. Pialkyl and $\mathrm{Pi}-\mathrm{Pi}$ interactions are represented by grey discontinuous lines). (C) Aspirin in the vicinity of SER 530 of COX-2. The acetyl group of Aspirin can be seen close to the serine residue in the model of cyclooxygenase enzyme

\section{DISCUSSION}

The therapeutic utility of non-steroidal antiinflammatory drugs (NSAIDs), especially such a well-established agent as aspirin is greatly hampered by a propensity to induce gastrointestinal tract (GIT) insult, particularly gastric ulceration [25]. Consequently, over the years, extensive research studies have been conducted in order to discover synthetic substitutes for NSAIDs free from ulcerogenic potential. The pharmacological activities of NSAIDs mainly derive from inhibition of cyclooxygenase (COX) enzymes (COX-1 and COX-2) [26]. Thus, nonselective blockade of COX enzymes by NSAIDs results in inhibition of not only prostaglandins that are induced in response to different inflammatory mediators, but also those which play an important role in normal physiological functions such as mucosal protection. Moreover, due to the acidic nature of classical NSAIDs, they produce localized erosion of the stomach mucosa [27]. Arising from these reasons, the excessive use of NSAIDs is linked with GIT adverse events and is mostly restricted.

To overcome the problems of NSAIDs, therefore we need better alternatives that not only have anti-inflammatory, antipyretic and antinociceptive properties but are also free from the side-effects that are commonly encountered with chronic use of NSAIDs. In this study, novel hydroquinone derivatives containing piperidine and pyrrolidine motifs were synthesized and assessed for antinociceptive, anti-inflammatory and antipyretic activities as well as their potential for ulcerogenic toxicity. The rationale for incorporating piperidine and pyrrolidine heterocycles into the hydroquinone structure was based on observations that these moiety containing compounds, when studied previously for ulcerogenic activity, they lacked the potential for instigating detectable ulcerogenicity $[22,28]$.

NSAIDs in general, but aspirin in particular, at one time, formed a basis for the management of moderate pain. In this respect, we compared the analgesic effect of our synthesized compounds with that of aspirin in the acetic acid induced abdominal constriction model of pain, which is commonly used for evaluating peripheral antinociceptive activity [29]. Pain is induced peripherally by the release of a variety of endogenous substances particularly mediators such as prostaglandins via the action of COX-1 and its isoform, COX-2 [30]. Additionally, local peritoneal nociceptive receptors are very much implicated in the abdominal constriction response [31]. Consequently, the current test compounds exhibited marked inhibitory activity on this 
nociceptive reaction suggesting the involvement of a peripheral analgesic effect which may well have been mediated via COX enzymes inhibition and/or local peritoneal nociceptors. In contrast, the hot plate test involves a spinal reflex as well as a more centrally located component which when inhibited, reflects central analgesic activity [32]. In our study however, the synthetic compounds did not produce a selective inhibition of thermal nociception. The findings therefore, lend support to the participation only of a peripheral antinociceptive effect in both cases.

Inflammation is the body's complex protective response involving tissue impairment caused by pathogens, mediators and noxious stimuli (chemical or physical) [33]. Therapy of inflammatory diseases is mainly based on interfering with different mediators that direct the host's response to injury [34]. In the current study, the hydroquinone derivatives were tested in the carrageenan-induced mouse paw edema assay. It is known that carrageenan induced paw edema is a tri-phasic event, ascribed to the release of different mediators including histamine and serotonin ( $1^{\text {st }}$ phase), bradykinin and prostaglandins ( $2^{\text {nd }}$ and $3^{\text {rd }}$ phase) [35]. The extended edema mitigating action (up to $5 \mathrm{~h}$ ) displayed by our novel compounds, might conceivably entail an inhibitory element on at least these four inflammatory mediators.

Pyrexia occurs due to an elevation of prostaglandin levels in the hypothalamus as an upshot of increased synthesis of this substance mediated by the release of pyrogenic cytokines in response to exogenous pyrogens [36]. Subcutaneous injection of Brewer's yeast imparts febrile effect and is considered as a classical method for the screening of potential antipyretics. Inhibition of prostaglandin synthesis via blockade of COX enzyme activity can be regarded as a possible mechanism of antipyretic action similar to that of NSAIDs [37]. Accordingly, the antipyretic outcomes are very promising as both compounds displayed strong antipyretic activity comparable to that of aspirin probably implicating prostaglandin inhibition.

The results of the ulcerogenicity evaluation revealed that the synthesized compounds possessed no propensity to incite gastric ulceration as compared to aspirin. Predictably, the ulcerative effects, as confirmed from the biochemical and histological parameters, were exacerbated in aspirin-treated animals. The nonselective COX enzyme inhibition, as well as acidic properties possessed by aspirin, are largely responsible for local gastric mucosal damage [27,38]. However, no significant changes in ulcer conducive conditions were observed in the case of the novel compounds indicating safe gastric profiles. In addition, the molecular docking study signified that both compounds disclosed a preferential COX-2 enzyme inhibitory capability which could possibly underlie their lack of ulcerogenic activity. Moreover, $\mathrm{pH}$ analysis of the test compounds revealed that they were basic in nature. This property might also play a key role in gastric safety because as acidic drugs like aspirin are present in an unionized state in the stomach. Consequently aspirin readily penetrates the gastric mucosa to cause gastric erosion and ulceration. Furthermore, the test compounds were generally well tolerated in the acute toxicity test since no mortality or behavioral discomfort was observed in doses up to $500 \mathrm{mg} / \mathrm{kg}$ and this manifested a favourable safety profile.

\section{CONCLUSION}

Novel hydroquinone derivatives functionalized with piperidine and pyrrolidine have been successfully synthesized. These compounds possess potent aspirin-like anti-inflammatory, analgesic and antipyretic activities, but they are devoid of gastric-ulcerogenicity. The absence of gastric toxicity may be due, in part, to preferential COX-2 enzyme inhibitory activity and basic rather than acidic chemical nature. Thus, the synthesized compounds may be superior therapeutic candidates for the management of pain, pyrexia and inflammation. However, further studies at the molecular level are required to establish these findings.

\section{DECLARATIONS}

\section{Acknowledgement}

The authors gratefully acknowledge the Sarhad University of Science and Information Technology, Peshawar, Pakistan for providing laboratory facilities related to the synthetic part of the study.

\section{Conflict of interest}

No conflict of interest is associated with this work.

\section{Contribution of authors}

The authors declare that this work was done by the authors named in this article and all liabilities pertaining to claims relating to the content of this article will be borne by them. 


\section{REFERENCES}

1. Chattopadhyay $M$, Velazquez $C A$, Pruski $A$, Nia $K V$, Abdellatif KR, Keefer $L K$, Kashfi $K$. Comparison between 3-Nitrooxyphenyl acetylsalicylate (NO-ASA) and O2-(acetylsalicyloxymethyl)-1-(pyrrolidin-1-yl) diazen-1-ium-1, 2-diolate (NONO-ASA) as safe antiinflammatory, analgesic, antipyretic, antioxidant prodrugs. J Pharmacol Exp Ther 2010; 335: 443-450.

2. Wallace JL, Keenan CM, Granger DN. Gastric ulceration induced by nonsteroidal anti-inflammatory drugs is a neutrophil-dependent process. Am J Physiol Gastrointest Liver Physiol 1990; 259: G462-G467.

3. Harirforoosh S, Asghar W, Jamali F. Adverse effects of nonsteroidal anti-inflammatory drugs: an update of gastrointestinal, cardiovascular and renal complications. J Pharm Pharm Sci 2014; 16: 821-847.

4. Bang SH, Han SJ, Kim DH. Hydrolysis of arbutin to hydroquinone by human skin bacteria and its effect on antioxidant activity. J Cosmet Dermatol 2008; 7: 189193.

5. Pegg RB, Rybarczyk A, Amarowicz R. Chromatographic separation of tannin fractions from a bearberry-leaf (Arctostaphylos uva-ursi L. Sprengel) extract by SEHPLC-a short report. Pol J food Nutr Sci 2008; 58: 485490.

6. Lee H-J, Kim K-W. Anti-inflammatory effects of arbutin in lipopolysaccharide-stimulated BV2 microglial cells. Inflamm Res 2012; 61: 817-825.

7. Taha MME, Salga MS, Ali HM, Abdulla MA, Abdelwahab SI, Hadi AHA. Gastroprotective activities of Turnera diffusa Willd. ex Schult. revisited: role of arbutin. J Ethnopharmacol 2012; 141: 273-281.

8. Cho JY. Suppressive effect of hydroquinone, a benzene metabolite, on in-vitro inflammatory responses mediated by macrophages, monocytes, and lymphocytes. Mediators Inflamm 2009; 2008: 1-11.

9. Joncour R, Duguet N, Métay E, Ferreira A, Lemaire M. Amidation of phenol derivatives: a direct synthesis of paracetamol (acetaminophen) from hydroquinone. Green Chem 2014; 16: 2997-3002.

10. Sakhteman A, Sharifzadeh $M$, Moradi $A$, Nadri $H$, Tabrizian K, Amanlou M, Asadipour A, Divsalar $K$ Shafiee A, Foroumadi A. Antinociceptive activity of some 1, 4-substituted piperidine derivatives using tail flick method in mice. Afr J Pharm Pharmacol 2011; 5 352-357.

11. Khanum SA, Girish V, Suparshwa S, Khanum NF. Benzophenone- $N$-ethyl piperidine ether analoguesSynthesis and efficacy as anti-inflammatory agent. Bioorg Med Chem Lett 2009; 19: 1887-1891.

12. Chen G, He H-p, Ding J, Hao $X-j$. Synthesis and antitumor activity evaluation of regioselective spiro [pyrrolidine-2, 3'-oxindole] compounds. Heterocycl Commun 2009; 15: 355-360.

13. He X, Alian A, Stroud R, Ortiz de Montellano PR. Pyrrolidine carboxamides as a novel class of inhibitors of enoyl acyl carrier protein reductase from
Mycobacterium tuberculosis. J Med Chem 2006; 49: 6308-6323.

14. Chen F. Synthesis and characterisation of some electroactive polymers. In.: Dublin City University; 1992.

15. Hollands $C$. The animals (scientific procedures) act 1986. Lancet 1986; 328: 32-33.

16. OECD guidelines. OECD (Organization for Economic Cooperation and Development) revised draft guidelines 423. OECD Guidelines for the Testing of Chemicals: Organization for Economic Co-operation and Development; 2001.

17. Collier H, Dinneen L, Johnson CA, Schneider C. The abdominal constriction response and its suppression by analgesic drugs in the mouse. $\mathrm{Br} J$ Pharmacol Chemother 1968; 32: 295-310.

18. Akbar S, Subhan F, Karim N, Shahid M, Ahmad N, Ali G, Mahmood W, Fawad K. 6-Methoxyflavanone attenuates mechanical allodynia and vulvodynia in the streptozotocin-induced diabetic neuropathic pain. Biomed Pharmacother 2016; 84: 962-971.

19. Winter CA, Risley EA, Nuss GW. Carrageenin-induced edema in hind paw of the rat as an assay for antiinflammatory drugs. Exp Biol Med 1962; 111: 544-547.

20. Ali G, Subhan F, Wadood A, Ullah N, Islam NU, Khan I. Pharmacological evaluation, molecular docking and dynamics simulation studies of salicyl alcohol nitrogen containing derivatives. Afr J Pharm Pharmacol 2013; 7: 585-596.

21. Martin M, Marhuenda E, Perez-Guerrero C, Franco J. Antiulcer effect of naringin on gastric lesions induced by ethanol in rats. Pharmacology 1994; 49: 144-150.

22. Ali G, Subhan F, Islam NU, Ullah N, Shahid M, Ullah S, Ullah I, Shah R, Khan I, Sewell RD. Comparative evaluation of gastroulcerogenic potential of nitrogen isoforms of salicyl alcohol and aspirin in rats: biochemical and histological study. Arch Pharm Res 2014; 37: 916-926.

23. Shahid M, Subhan F, Ullah I, Ali G, Alam J, Shah R. Beneficial effects of Bacopa monnieri extract on opioid induced toxicity. Heliyon 2016; 2: e00068.

24. Trott O, Olson AJ. AutoDock Vina: improving the speed and accuracy of docking with a new scoring function, efficient optimization, and multithreading. J Comput Chem 2010; 31: 455-461.

25. Lanas Á, Carrera-Lasfuentes $P$, Arguedas $Y$, García $S$, Bujanda L, Calvet X, Ponce J, Perez-Aísa Á, Castro M, Muñoz M. Risk of upper and lower gastrointestinal bleeding in patients taking nonsteroidal antiinflammatory drugs, antiplatelet agents, or anticoagulants. Clin Gastroenterol Hepatol 2015; 13: 906-912. e902.

26. Simmons DL, Botting RM, Hla T. Cyclooxygenase isozymes: the biology of prostaglandin synthesis and inhibition. Pharmacol Rev 2004; 56: 387-437.

27. Langman MJ. Adverse effects of conventional non-steroidal anti-inflammatory drugs on the upper gastrointestinal tract. Fundam Clin Pharmacol 2003; 17: 393-403.

Trop J Pharm Res, January 2018; 17(1): 62 
28. Kammerer F-J, Schleyerbach R. Isoxazole derivatives and medicaments containing these compounds. In.: Google Patents; 1987.

29. Sudo RT, Neto ML, Monteiro CE, Amaral RV, Resende ÂC, Souza PJ, Zapata-Sudo G, Moura RS. Antinociceptive effects of hydroalcoholic extract from Euterpe oleracea Mart.(Açaí) in a rodent model of acute and neuropathic pain. BMC Complement Altern Med 2015; 15: 208.

30. Matsumoto H, Naraba H, Ueno A, Fujiyoshi T, Murakami $M$, Kudo I, Oh-ishi S. Induction of cyclooxygenase-2 causes an enhancement of writhing response in mice. Eur J Pharmacol 1998; 352: 47-52.

31. Bentley G, Newton S, Starr J. Studies on the antinociceptive action of $\alpha$-agonist drugs and their interactions with opioid mechanisms. $\mathrm{Br} J$ Pharmacol 1983; 79: 125-134.
32. Jinushi K, Kushikata $T$, Kudo $T$, Calo G, Guerrini $R$, Hirota K. Central noradrenergic activity affects analgesic effect of Neuropeptide S. J Anesth 2017: 1-6.

33. Weiss U. Inflammation. Nature 2008; 454: 427.

34. Gilroy DW, Lawrence $T$, Perretti M, Rossi AG. Inflammatory resolution: new opportunities for drug discovery. Nat Rev Drug Discov 2004; 3: 401-416.

35. Rosa M. Biological properties of carrageenan. J Pharm Pharmacol 1972; 24: 89-102.

36. Bleeker-Rovers CP, van der Meer JWM, Beeching NJ. Fever. Medicine 2009; 37: 28-34.

37. Netea MG, Kullberg BJ, Van der Meer JW. Circulating cytokines as mediators of fever. Clin Infect Dis 2000; 31: S178-S184.

38. Tomisato W, Tanaka K-i, Katsu T, Kakuta H, Sasaki K, Tsutsumi S, Hoshino T, Aburaya M, Li D, Tsuchiya T. Membrane permeabilization by non-steroidal antiinflammatory drugs. Biochem Biophys Res Commun 2004; 323: 1032-1039. 